\title{
Non-invasive evaluation of placental blood flow: lessons from animal models
}

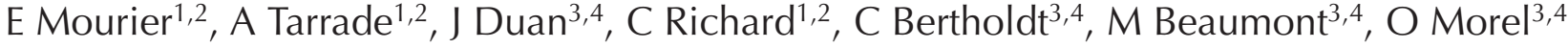 \\ and P Chavatte-Palmer ${ }^{1,2}$ \\ ${ }^{1}$ UMR BDR, INRA, ENVA, Université Paris Saclay, Jouy en Josas, France, ${ }^{2}$ PremUp Foundation, Paris, France, \\ ${ }^{3}$ IADI, Inserm U947, University of Lorraine, CHRU of Brabois, Nancy, France, and ${ }^{4} \mathrm{CHRU}$ of Nancy, pole de \\ Gynécologie Obstétrique, Nancy, France \\ Correspondence should be addressed to E Mourier; Email: eve.mourier@inra.fr
}

\begin{abstract}
In human obstetrics, placental vascularisation impairment is frequent as well as linked to severe pathological events (preeclampsia and intrauterine growth restriction), and there is a need for reliable methods allowing non-invasive evaluation of placental blood flow. Uteroplacental vascularisation is complex, and animal models are essential for the technical development and safety assessment of these imaging tools for human clinical use; however, these techniques can also be applied in the veterinary context. This paper reviews how ultrasound-based imaging methods such as 2D and 3D Doppler can provide valuable insight for the exploration of placental blood flow both in humans and animals and how new approaches such as the use of ultrasound contrast agents or ultrafast Doppler may allow to discriminate between maternal (non-pulsatile) and foetal (pulsatile) blood flow in the placenta. Finally, functional magnetic resonance imaging could also be used to evaluate placental blood flow, as indicated by studies in animal models, but its safety in human pregnancy still requires to be confirmed.

Reproduction (2017) 153 R85-R96
\end{abstract}

\section{Introduction}

Placental vascularisation impairment occurs in more than $15 \%$ of pregnancies in humans, leading to placental insufficiency, including potentially severe disease such as preeclampsia (PE, 4-7\%) or intrauterine growth restriction (IUGR, 10\%). These pathologies account for $20-30 \%$ of prenatal and perinatal morbidity and mortality in humans and are also associated with increased risk of developing a metabolic syndrome at adulthood (Barker et al. 2002). Precocious screening for the diagnosis of women at risk of developing placental insufficiency is therefore of uppermost importance but remains unsatisfactory. There is, thus, a crucial health interest to develop reliable methods for non-invasive evaluation of placental blood flow in the human obstetrics context.

\section{Uteroplacental vascularisation in humans and animals}

Uteroplacental vascularisation is very complex (Jaffe et al. 1997, Charnock-Jones et al. 2004, Mayhew et al. 2004). In humans, the placenta is discoid, haemochorial and villous. The afferent vascularisation originates predominantly from the uterine arteries.
The spiral arteries, located in the myometrium, are remodelled by extravillous trophoblastic cells shortly after implantation. These cells replace the endothelial lining of the arteries and form trophoblastic plugs, preventing maternal blood from entering the intervillous space throughout the first trimester (Jaffe et al. 1997). In one study, colour Doppler imaging demonstrated blood flow within the uteroplacental circulation in pregnancies starting from 7 weeks of gestation (Jaffe 2001). Whether the detected flow in the early placenta results only from foetal circulation remains unknown to date. The plugs gradually dissolve to let maternal blood enter the intervillous space at the end of the first trimester. Concomitantly, the spiral arteries dilate and lose their vasoconstrictive characteristics. Moreover, a dense anastomotical vascular network (arteriovenous shunt) develops in the myometrium located under the placenta, as demonstrated using 3D colour Doppler techniques (Schaaps \& Tsatsaris 2001). Simultaneously, on the foetal side, the chorionic villous tree expands, linked to the foetus through the umbilical cord (Fig. 1).

Placental vascularisation can be evaluated indirectly by the assessment of uterine or umbilical artery blood flow or by directly imaging the placenta, as described in this review (Fig. 2). For obvious ethical reasons, the testing of functional imaging techniques is limited in 


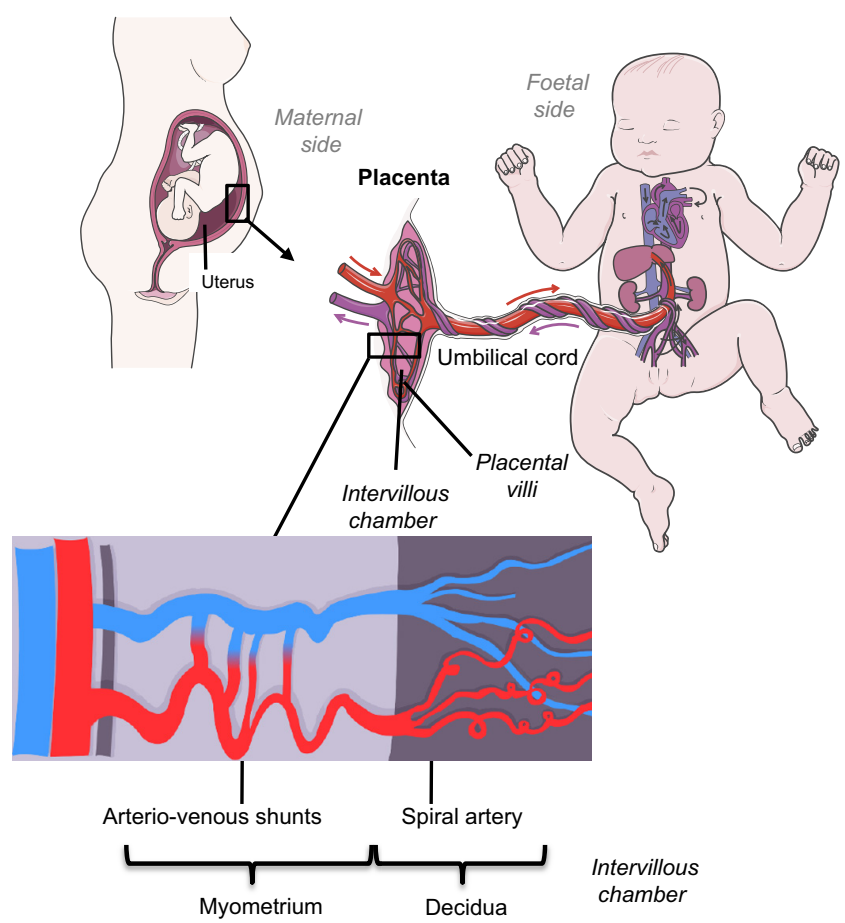

Figure 1 Utero-foeto-placental vascularisation in human. The human placenta is haemochorial and of discoid shape. Placental villi are directly in contact with maternal blood into the intervillous chamber. An arterio-venous shunt is present into the myometrium under the placenta. Adapted from Burton et al. (2009).

pregnant women. As a consequence, animal models are needed. Nevertheless, there is no such placentation as human placentation and intimate knowledge of the anatomic and physiological characteristics for each species is needed (Chavatte-Palmer \& Tarrade 2016).

Despite their resemblance to humans, the use of non-human primates (NHP) is greatly limited owing to
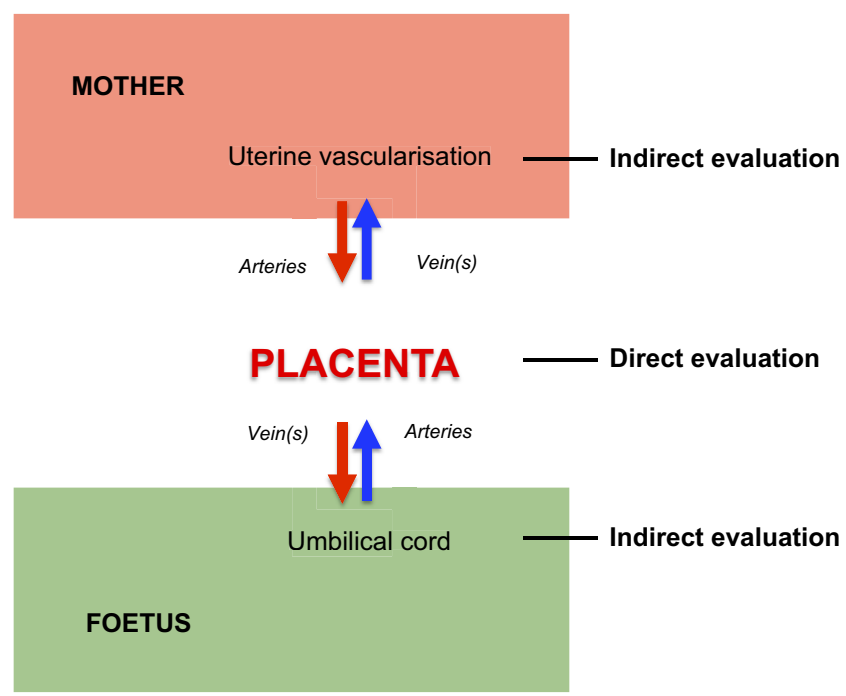

Figure 2 General scheme of placental vascularisation evaluation. important ethical questions and high cost. Because of their haemochorial placenta of discoid shape, close to that of humans, rodents and lagomorphs are naturally favoured as models. Rodents are relatively cheap, easy to handle and offer a wide range of genetic tools. Rabbits are larger with a placental structure closer to that of humans than rodents. Nevertheless, in both rodents and rabbits, the exchange zone is of labyrinthine structure (mesh-like), in contrast to the villous structure of the human placenta. Although ruminant placentation is very different (cotyledonary placentation), sheep are often used for obstetrical research due to their long gestation (5 months) and large size, allowing the use of medical imaging equipment. Pigs, horses and carnivores are generally excluded for biomedical purposes due to their very different placental structures compared to humans, although information generated in these species when used may also be relevant to infer general principles in placental imaging (Fig. 3). Finally, blood flow to the placenta varies according to species' size, placental morphology and gestational age (Table 1).

\section{Non-human primates}

Among NHPs, large primates could be considered as the gold standard because of their important similarities to humans such as maternal blood circulation in the intervillous space and spiral artery remodelling. The baboon is particularly interesting because uteroplacental ischaemia provoked by uterine artery ligation in pregnancy in this species leads to signs of PE (Makris et al. 2007). In rhesus macaques, it is important to notice that the placenta possesses two lobes (vs a single lobe in humans) (Roberts et al. 2012).

\section{Rodents and lagomorphs}

In mice, definitive placentation only occurs at midterm of a very short pregnancy (18-19 days). Trophoblastic invasion of maternal arteries is shallow and limited to proximal decidua, thus reducing this species' use for investigating arterial remodelling (Carter 2007). In contrast, the rat is considered an appropriate model for studying the mechanisms of decidualisation as well as subsequent remodelling of the uterine tissues (Fonseca et al. 2012). Although there is no known equivalent of PE in animals, many transgenic, surgical or pharmaceutical mouse and rat models have been developed, which mimic some aspects of PE (Clark 2014).

In rabbits (31-32 days gestation), long spiral arteries perfuse both myometrium and placenta (Duncan \& Lewis 1969). Before reaching the labyrinth, maternal blood is released in arterial sinuses located in the decidual part of the placenta, slowing down blood flow to promote transplacental exchange in the placental labyrinth. Blood from the labyrinth is collected by an extensive decidual venous system (Carter et al. 1971). 


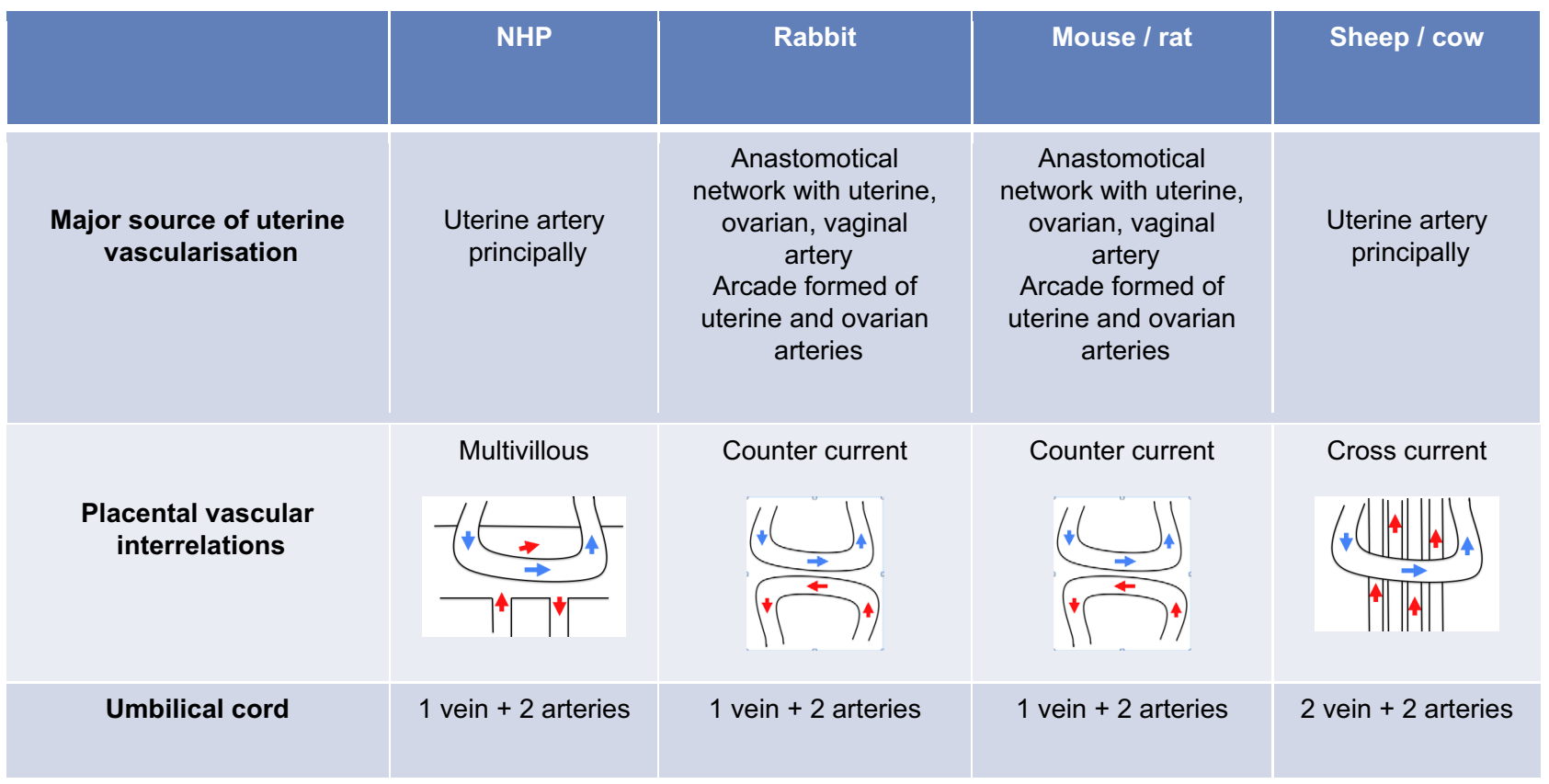

Figure 3 Comparative inter-species utero-foeto-placental vascularisation (Barone 1978, Evain-Brion 2010).

\section{Sheep}

In sheep, placental angiogenesis begins as early as day 18 (Reynolds \& Redmer 1995, Bairagi et al. 2016). Each placental unit (placentome, $N=70-100$ ) consists of a maternal caruncle with close interdigitation with the foetal cotyledon. Maternal caruncular vascularity increases gradually throughout gestation, whereas foetal cotyledonary vascularity expands slowly until midterm and then intensively during the last third of gestation. Maternal caruncular tissues are characterised near term by large capillaries, reducing blood flow velocity and thus promoting transplacental exchange. Placentation in goats and cattle is also cotyledonary and shares many similarities with that of sheep.

Given the complexity of placental vascularisation, it is impossible to mimic placental hypoperfusion in animals as in humans perfectly. Placental perfusion can be disturbed, however, using many different approaches. For example, in NHP, a decrease in the volume of placental blood flow associated to placental infarctions was reported in overnourished pregnant Japanese macaques (Frias et al. 2011). In rodents, a decrease in maternal uteroplacental blood flow has been obtained by feeding rat dams with a lowsodium diet over the last week of gestation, which was also associated with foetal IUGR (Bibeau et al. 2016). Inducing elevated maternal testosterone concentrations (Gopalakrishnan et al. 2016) or bilateral uterine artery ligation in the rat (Nusken et al. 2008) also reduces placental perfusion. In rabbits, placental hypoperfusion was obtained by the inhibition of nitric oxide synthase using NG-nitro-L-arginine methylester (L-NAME) (Lecarpentier et al. 2012, Tarrade et al. 2014) or by selective ligature of uteroplacental vessels

Table 1 Mean uteroplacental blood flow (UBF) measured in model animal species, before and during pregnancy.

\begin{tabular}{|c|c|c|c|c|}
\hline & $\begin{array}{l}\text { UBF non pregnant (NP) or } \\
\text { beginning of pregnancy (day) }\end{array}$ & References & UBF end of pregnancy (day) & References \\
\hline Rabbit & $3-5 \mathrm{~mL} / \mathrm{min}(\mathrm{NP}$ to day 10$)$ & Nesbitt et al. (2005) & $18-30 \mathrm{~mL} / \min$ (day 28) & $\begin{array}{l}\text { Carter et al. (1971), } \\
\text { Nesbitt et al. (2005), } \\
\text { McArdle et al. (2009) }\end{array}$ \\
\hline Mouse & NA & & $\begin{array}{l}100-180 \mathrm{~mL} / \mathrm{min} / 100 \mathrm{~g} \text { of } \\
\text { placental tissue (day } 16) \\
0.35 \mathrm{~mL} / \mathrm{min} \text { (day } 17.5)\end{array}$ & $\begin{array}{l}\text { Salomon et al. (2005, 2006), } \\
\text { Taillieu et al. (2006) } \\
\text { Kulandavelu et al. (2013) }\end{array}$ \\
\hline Rat & $0.5 \mathrm{~mL} / \mathrm{min}$ & Lashley et al. (2015) & $\begin{array}{l}159 \mathrm{~mL} / \mathrm{min} / 100 \mathrm{~g} \text { of placental } \\
\text { tissue }\end{array}$ & Deloison et al. (2012) \\
\hline & & & $2.1 \mathrm{~mL} / \mathrm{min}$ (day 20 ) & Lashley et al. (2015) \\
\hline $\begin{array}{l}\text { Sheep } \\
\text { Macaque }\end{array}$ & $180 \mathrm{~mL} / \mathrm{min}$ (day 30) & $\begin{array}{l}\text { Reynolds and Redmer (1995) } \\
\text { Keator et al. (2011) }\end{array}$ & 1500 mL/min (day 145) & Reynolds and Redmer (1995) \\
\hline Human & $60 \mathrm{~mL} / \mathrm{min}$ (1 st trimester) & & $\begin{array}{c}800 \mathrm{~mL} / \mathrm{min}(3 \mathrm{rd} \text { trimester); } \\
176 \mathrm{~mL} / 100 \mathrm{~g} / \mathrm{min}\end{array}$ & Gowland et al. (1998) \\
\hline
\end{tabular}

NA, not available. 
(40-50\%) (Eixarch et al. 2011). In sheep, modulation of placental perfusion was obtained by altering maternal diet (Wallace et al. 2008, Redmer et al. 2009, Ma et al. 2010), by surgical removal of uterine caruncles prior to pregnancy (Robinson et al. 1979) or by inducing maternal hyperthermia (Bell et al. 1989).

In the following paragraphs, the current approaches for non-invasive evaluation of placental blood flow and how animal models contribute to technical development for human clinical use are described.

\section{Techniques used to evaluate placental blood flow in vivo}

Because it is widely available, low-cost and innocuous, Doppler is the first-line technique for the evaluation of uteroplacental blood flow. The Doppler technology is based on the analysis of the change in frequency or intensity of ultrasound waves when they are reflected by a moving target such as erythrocytes. It is used to study blood flow in arteries and veins and to evidence modifications due to artery stiffening or reduction in blood vessel volume. Alternatively, magnetic resonance imaging (MRI) with or without injection of ferro-magnetic contrast agents may also be used to explore placental blood flow, whereas methods based on X-ray imaging are generally banned due to the possible damage to the growing foetus (Fig. 4).

\section{Indirect evaluation of placental blood flow using 2D Doppler}

Placental blood flow can be assessed with Doppler ultrasound using maternal (uterine artery; UtA) and foetal circulation (umbilical artery; UmA) as an indirect estimate of placental function (Gudmundsson et al.2009). Two Doppler modes are used: colour Doppler (CD) is based on the colour-coding of blood flow according to velocity, and pulse wave Doppler (PWD) is based on the spectral analysis of the Doppler signal. CD enables blood flow imaging over an entire region of interest without quantification. PWD allows the quantification of flow characteristics through the measurement of peak or mean flow velocity or resistance and pulsatility indices ( $\mathrm{RI}$ and $\mathrm{PI}$, respectively). In practice, $\mathrm{PI}$ is the most extensively used. Those modes are displayed in real time at frame rates that are usually quite low (approximately a few hertz) (Tanter \& Fink 2014).

The utero-foeto-placental blood flow is linked to the gross morphology (size and shape) of the placenta (Salavati et al. 2016). In clinics, UtA Doppler flow (mean $\mathrm{PI}$ of the left and right arteries) provides a proxy measurement for the degree of vascular remodelling. Moreover, when the foetal villous vasculature of the placenta is damaged, vascular resistance within the placenta increases, leading to increased UmA RI (Llurba et al. 2013). The flow velocity waveform of UtA evolves physiologically from a high resistance prior to

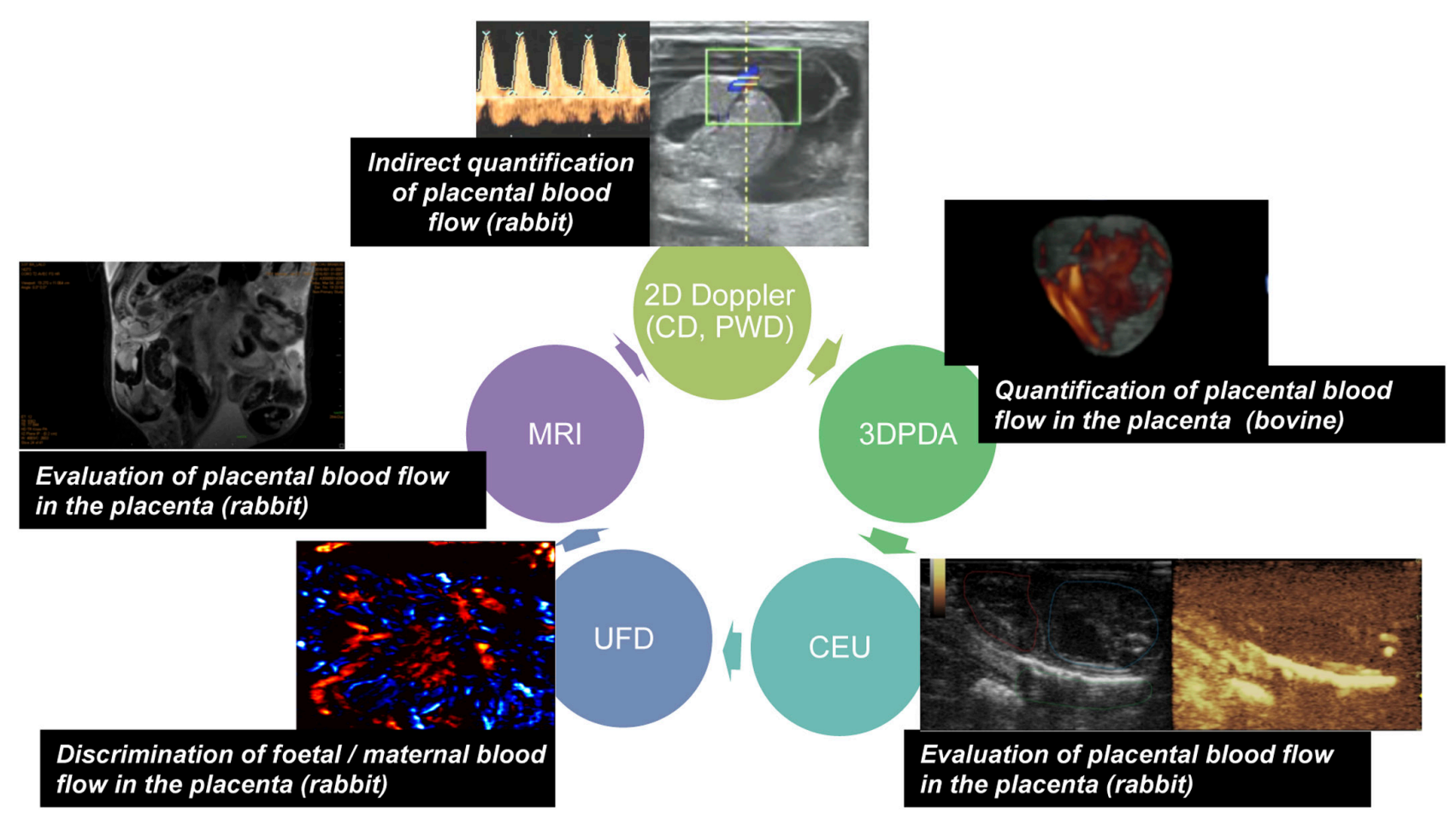

Figure 4 Current approaches for non-invasive evaluation of placental blood flow. The 5 most important methods are 2D Doppler with colour Doppler (CD) and pulse-wave Doppler (PWD), 3D power Doppler angiography (3DPDA), contrast-enhanced ultrasound (CEU), ultrafast Doppler (UFD) and magnetic resonance imaging (MRI). Examples of the obtained image are given in various model species. 
pregnancy to a low resistance flow pattern in the first half of pregnancy (invasion of the maternal vessels by the trophoblast). Persistence of high resistance patterns in the UtA at mid-gestation have been associated with increased risk of obstetric complications. The flow velocity waveform of UmA is normally that of low resistance in the last trimester of pregnancy, reflecting the villous vascular tree development, whereas a high resistance pattern indicates abnormal growth of the tertiary villi. In a prospective cohort study of 2120 women, both UtA and UmA Doppler flow velocity waveforms were associated with different aspects of the size and shape of the placenta after birth, both in relation with foetal growth rate (Savasan et al. 2014). In humans, however, there is no evidence that the use of UmA Doppler or a combination of UmA and UtA Doppler in low-risk or unselected populations benefits either mother or baby (Alfirevic et al. 2015). Therefore, UtA and UmA Doppler measurements are not used in routine examinations, but can be used at any time when a pathological condition is suspected, although their interest for predicting PE remains controversial (Savasan et al. 2014, Zhu et al. 2015).

This approach has been successfully used in numerous animal species, as a basis for preclinical studies or to monitor high-risk pregnancies in veterinary medicine. In rabbits (Polisca et al. 2010), bitches and queens (Nautrup 1998, Di Salvo et al. 2006, Scotti et al. 2008, Giannico et al. 2014), normal ranges of UtA and UmA blood flow parameters have been detailed throughout pregnancy, as well in mice using high-frequency ultrasound (Hernandez-Andrade et al. 2014). In both rabbits and mice, they were also used to compare functional haemodynamic changes of the placenta in pathophysiologic conditions (Venditti et al. 2013, Lopez-Tello et al. 2015, Valentino et al. 2016). In any case, differences in blood flow could vary depending on foetal number $(U t A)$ and foetal position in the uterine horn $(U m A)$, limiting the use of these multicotous species as models for humans. In cattle and horses, UtA blood flow can be monitored with transrectal Doppler ultrasound and appears valuable for monitoring highrisk pregnancies (Panarace et al. 2006, Klewitz et al. 2015). In these species, the reliability of the Doppler exam of foetal and placental blood flow, however, depends on the operator's technical skills, on foetal and maternal movements and on the presence of gas in the gut. Moreover, the stress induced by the examination procedure may impair haemodynamic data.

\section{Three-dimensional power Doppler angiography (3DPDA)}

Placental perfusion can be directly investigated with three-dimensional power Doppler angiography (3DPDA). 3DPDA is a combination of threedimensional ultrasound (3DUS) and power Doppler
(PD) techniques. Using 3DUS, a region of interest (ROI) is scanned and a 3D reconstruction obtained either by manual drawing or automatically. With the PD mode, movements are detected through the comparison of pixels in successive B-images, resulting in colour cartography of global amplitude of erythrocyte movement. PD is well adapted to quantify vascularisation in the placenta because its sensibility to slow flows and small vessels is high. 3DUS and PD mode can be associated: acquired volumes or a virtual biopsy of these volumes can be analysed quantitatively using VOCAL software (virtual organ computer analysis, General Electrics Healthcare). The perfusion within the ROI is not defined in terms of $\mathrm{mL} / \mathrm{min}$ or vascular resistance indexes, but using three specific indices. The vascularisation index $(\mathrm{VI})$ is the ratio of colour/grey voxels and estimates the percentage of blood vessels within the ROI, the flow index $(\mathrm{FI})$ represents the mean power Doppler signal intensity value and represents placental blood flow and the vascularisation flow index $(\mathrm{VFI}=\mathrm{VI} \times \mathrm{FI} / 100)$ represents tissue perfusion. $\mathrm{FI}$ and VFI are expressed as absolute values between 0 and 100 . The correlation between perfusion to the uteroplacental unit and quantitative 3DPD indices was confirmed in a sheep model (Morel et al. 2010). Because of the heterogeneity of intraplacental vascularisation (Tuuli et al. 2011), manual drawing of the whole organ provides more reproducible results than the automatic drawing mode, although it is more time consuming (Cabezas López et al. 2016). Due to the size and shape variation, however, the complete placenta cannot always be scanned. Nevertheless, in women, a large volume of both placenta and myometrium can be examined (Morel et al. 2011). The resolution is about $0.3 \mathrm{~mm}$. Qualitatively, it is possible in the $3 \mathrm{rd}$ trimester to visualise branches of principal placental vessels down to tertiary villous vessels. Quantitatively, changes in intraplacental blood flow seem to appear precociously compared to increased UmA RI observed using 2D Doppler (Matijevic \& Johnston 1999). 3D power Doppler indices were studied in normal pregnancies, and reference values are available for physiological situations (De Paula et al. 2009, Pomorski et al. 2014). One drawback is that foetal blood flow cannot be differentiated from maternal blood flow.

In humans, 3DPDA has been extensively tested in the 2nd trimester. Findings suggest that it has the potential to identify women at risk for subsequent development of PE in the 2nd (Neto \& Ramos 2016) and in 3rd trimester (Guiot et al. 2008, Duan et al. 2016). Current research, however, focuses on its early prognostic value in the hope that 3DPDA may constitute a new tool for 1 st trimester intraplacental flow analysis (Tonni et al. 2015, Cabezas López et al. 2016). Indeed, at this stage, the complete vascular tree can be assessed, theoretically providing a very accurate analysis of placental vascularisation. In a prospective study between 10 and 13 weeks 
of pregnancy, using the sphere biopsy mode, it was shown that 1 st trimester patients who later develop PE have lower 3DPDA indices than healthy controls, suggesting 3DPDA can help predict PE (Dar et al. 2010). Technically, the quantification of the vascularisation is more representative of real perfusion when the largest portion of the uteroplacental unit is included within the volume of interest (Morel et al. 2011).

Animal models have been used to explore this new approach. Using experimental reduction of placental perfusion with L-NAME in rabbits, quantitative 3DPDA indices were demonstrated to be sensitive enough to detect placental vascular deficiency (Lecarpentier et al. 2012) as confirmed subsequently by ex vivo stereological approaches (Tarrade et al. 2014, Valentino et al. 2016).

This relatively new approach enables the direct evaluation of the organ of interest and is safe during pregnancy, as contrast agents or exposure to radiation is not needed. Its potential for early screening for PE needs to be confirmed. So far, however, GE equipment and VOCAL software are needed for clinical use of 3DPDA, and the indices provided by the software are not a universal method of quantification (in contrast to blood flow quantification in $\mathrm{mL} / \mathrm{min} / \mathrm{g}$ of placenta, for example). Moreover, the exploration field of transducers become limited with increased placental size as pregnancy advances. Physical characteristics of the patient (due to attenuation of ultrasounds with increasing depth) and machine settings (power Doppler gain, pulse repetition frequency and wall motion filter) may also affect 3DPDA indices and limit comparison between patients. Finally, as any real-time ultrasound technique, this method remains operator dependent.

\section{Contrast-enhanced ultrasound (CEU)}

Because of the difference of density between tissue and gas, ultrasounds are entirely reflected by gaseous volumes. This physical characteristic has been used to develop the gas-filled, lipid-encapsulated microbubbles as injectable ultrasound contrast agents. Contrast-enhanced ultrasound (CEU) enhances the grey scale or colour Doppler mode signal, thus enabling the visualisation of vascularisation down to the microvascular perfusion. The mean diameter of microbubbles ranges from 2 to $8 \mu \mathrm{m}$, less than that of a red blood cell but sufficiently large to be trapped within the vascular space (Roberts et al. 2016). Thus, this technique could discriminate foetal and maternal circulatory systems by imaging the intervillous space (IVS) alone and could be used to diagnose the abnormalities of placental blood flow (Abramowicz 1997).

Because of non-elucidated safety issues, however, ultrasound contrast agents are not currently used in on-going human pregnancies. In one very recent study, CEU was used in macaques and in human pregnancy immediately before scheduled first-trimester termination. Examination of placentas by electron microscopy showed no evidence of ultrastructure damage to microvilli syncytiotrophoblast and indicated that the use of CEU does not results in placental structural damage and may offer a safe clinical tool (Roberts et al. 2016). Studies in macaques and rats also suggest that CEU is safe (Keator et al. 2011, Roberts et al. 2016), without significant effects either on foetal circulation (Schmiedl et al. 1998) or on foetal weight (Arthuis et al. 2013). One study, however, suggests that it may affect placenta. Indeed, in pregnant rats submitted to CEU in combination with Evans blue perfusion, the amount of Evans blue in the placenta was much higher when CEU was used compared to ultrasound only or contrast agent only, suggesting that ultrasound combined with micro-bubbles can induce cavitation, affecting the permeability of blood vessels and inducing Evans blue leakage (Hua et al. 2009).

In humans, CEU was used to analyse changes in blood flow after injection of vasoactive products in the ex vivo-perfused term human placenta, in association with colour Doppler imaging and spectral analysis (Abramowicz et al. 1999). Clinically, when placental perfusion was visualised at 11 weeks of gestation immediately before scheduled first-trimester pregnancy termination, CEU demonstrated that there are regional differences in intervillous space perfusion within an individual placenta (Roberts et al. 2016).

CEU has been used in NHP and mice for fundamental and/or biomedical purposes. Maternal circulation in the placenta was visualised during the last third of pregnancy in macaques (Schmiedl et al. 1998). More recently, a study using rhesus monkeys showed that CEU used with grey scale harmonic imaging (enabling detection of blood flow without requiring the use of Doppler methods) allowed the visualisation of maternal blood flow in the IVS only, thus separating maternal from foetal blood flow (Ragavendra \& Tarantal 2001). A study in cynomolgus monkeys showed the interest of contrast agents to visualise and quantify intervillous blood flow during early pregnancy (Simpson et al. 1998). Technically, ultrasound exams were performed trans-abdominally with a $7 \mathrm{MHz}$ linear array probe, and the flow of blood into and out of the intervillous compartment was readily assessed and quantified using pulsed and colour Doppler. A pulsed-wave Doppler gate was placed in the intervillous compartment, and the waveforms obtained from the IVS were expressed quantitatively using PI (Simpson et al. 1998).

Others have used time-intensity curves and software indices to quantify blood in the IVS in humans undergoing second-trimester pregnancy termination (Poret-Bazin et al. 2013). In these cases, the bolus mode (immediately after an injection of a bolus of contrast agent) or the destruction-replenishment method can be used. In the latter, after the micro-bubbles are homogeneously distributed through the placenta, high 
power pulses are emitted that burst bubbles locally. The replenishment of the contrast is subsequently recorded and analysed using a multi-pulse contrast-specific algorithm derived from modelling time-intensity data acquired after acoustic destruction of micro-bubbles, providing highly accurate estimates of microvascular blood volume and velocity. The combination of the two approaches provides spatial and quantitative information on vascular perfusion in the region of interest (Arthuis et al. 2013). Using Japanese macaques, CEU imaging after a micro-bubble burst demonstrated that the rate of perfusion increases with advancing gestation in the 2nd trimester of pregnancy (Roberts et al. 2016). In macaques during early pregnancy, CEU and Doppler were combined to calculate blood flow in a manually identified ROI and subsequently quantify volume $(\mathrm{mL} / 100 \mathrm{~mL})$, flow rate $(\mathrm{s}-1)$ and blood flow $(\mathrm{mL} / \mathrm{min} / \mathrm{g})$ (Keator et al. 2011). Finally, in rats, CEU has been used for quantitative analysis of placental perfusion through the visualisation of the central arterial canal (Zhou et al. 2013) and to compare uteroplacental perfusion between controls and a rat model of PE (Yan et al. 2014).

\section{Ultrafast Doppler (UFD)}

A technologically disruptive solution to perform blood flow imaging and quantification has been recently proposed under the terminology ultrafast Doppler (UFD). In conventional ultrasound Doppler methods, due to a relatively low frame rate, a balance must be found between spatial resolution (full quantitative Doppler information is obtained on a limited sample volume with PWD) and temporal resolution (an averaged Doppler velocity and/or power estimation is obtained on a large region of interest with $C D$ ). By increasing the frame rate by $\times 100$, UFD offers the possibility to analyse the flow with a high spatio-temporal resolution and enables the acquisition of hundreds of samples simultaneously at several locations over a large field of view, thus providing new information about the flow behaviour (Tanter \& Fink 2014). The whole ultrasonic information required to assess the two-dimensional behaviour of the flow is acquired, and the PWD information was processed for each pixel within the wide two-dimensional field. Thus, with its very high frame rates applied to a wide field of view, UFD relies on both advantages of CD and PWD in a single mode, i.e. respectively imaging and quantification (Udesen et al. 2008, Bercoff et al. 2011).

In a recent preliminary study carried out on pregnant rabbits $(n=4)$, both imaging and quantification capacity of UFD were used to map placental blood flow (Osmanski et al. 2015) (Fig. 5). It is important to note that, within the labyrinth, blood flow characterised as foetal was not negligible compared to blood flow characterised as maternal.

\section{Magnetic resonance imaging (MRI) of the placenta}

Magnetic resonance imaging (MRI) is a technique of choice for the anatomical visualisation of soft tissues. It was applied to the placenta first for the diagnosis of placenta accreta (when the invasive trophoblast reaches the myometrium) and provides beneficial information in case of posterior placental implantation or of maternal obesity when ultrasounds cannot reach deeply to the placenta. Functional aspects such as vascularisation can be assessed by functional MRI (fMRI) techniques.

MRI is based on the physical phenomenon called nuclear magnetic resonance. Magnetic properties of an atom's nucleus such as its spin are linked to its number of protons and neutrons, allowing it to react to an external magnetic field, absorbing and emitting energy

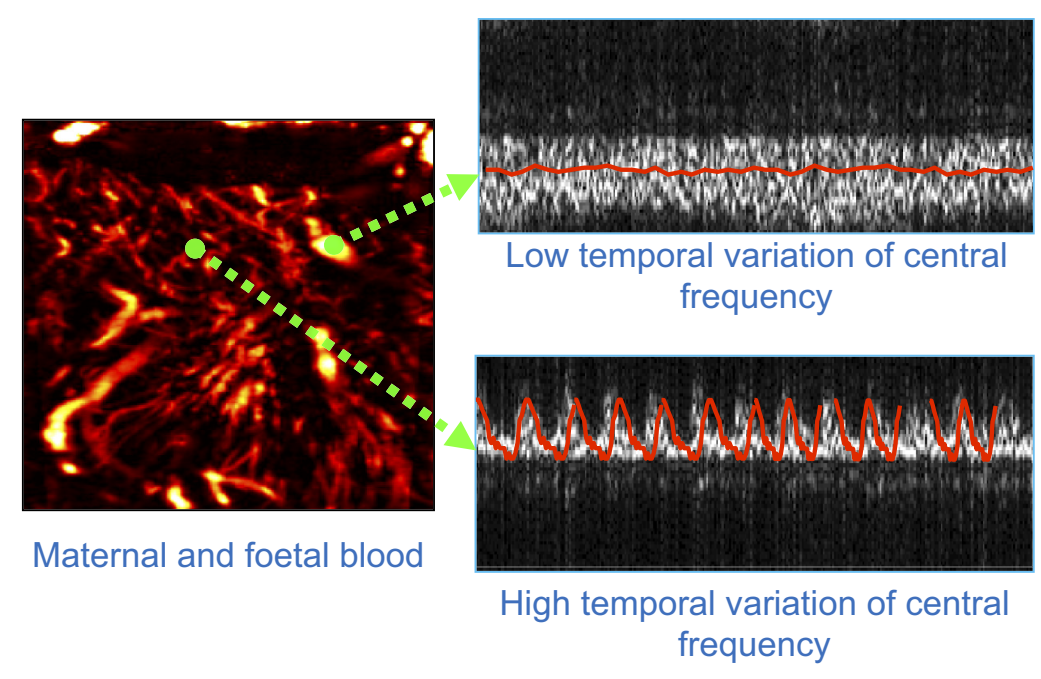

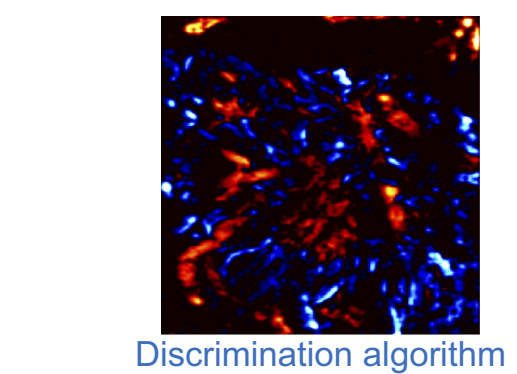

(blue: foetal blood, red: maternal blood)

Figure 5 Placental blood flow mapping with discrimination of foetal and maternal circulation using ultrafast Doppler (UFD) in the rabbit model (Osmanski et al. 2015). With UFD, the pulsatility of each placental vessel is analysed. Discrimination between maternal and foetal blood flows is performed using specific algorithms. 
as it comes back to their equilibrium state (relaxation). The nuclear resonance of Hydrogen $(\mathrm{H})$ atoms in water trapped in biological tissues is used for MRI. During a MRI exam, the body is first submitted to a high constant magnetic field, leading to the alignment (polarisation) of the magnetic nuclear spins. Then, another variable magnetic field is applied, perpendicular to the first one, causing a shift of the alignment of nuclear spins. According to their composition, tissues react differently to these magnetic fields and will behave differently in terms of energy emission. The capture of the tissue's response is converted to image. Different sequences of magnetic fields can be applied, and $\mathrm{T} 1$ relaxation times (longitudinal relaxation time of water protons after a pulse of radiofrequency) and T2 relaxation times (transverse relaxation time of water protons after a pulse of radiofrequency) are studied. The precision of the images increases with the intensity of the magnetic field, which is measured in Tesla $(\mathrm{T})$.

Paramagnetic compounds such as gadolinium are often used to enhance tissue contrast in areas that are difficult to visualise. In particular, dynamic contrast enhancement (DCE) MRI is used to explore and quantify tissue perfusion. It requires the acquisition of serial images, before, during and after the administration of the contrast agent, which allows a complete description of the contrast kinetics within tissues (Fig. 6). Thus, each sequence, with different contrasts, provides different information, allowing the imaging of the different tissues.

Animals are used to develop the techniques and to assess its safety. MRI is so far not yet applied in veterinary medicine in the field of reproduction and development, probably because of its cost and complexity (Dekan et al. 2012). Experimental studies in rats (Mevissen et al. 1994) and retrospectives studies in humans (Tocchio et al. 2015) are in favour of probable safety of MRI exams during pregnancy, although MRI uses large static and changing magnetic fields. Nevertheless, precautionary principles are currently applied, avoiding MRI exams during pregnancy unless needed under life-threatening conditions (Kanal et al. 2013) as well as gadoliniumbased contrast agents, which are known to cross the placenta (Muhler et al. 2011).

In any case, this technique is giving promising insight into placental function in vivo. In mice and rats, DCE MRI was used to quantify placental perfusion during the last third of pregnancy (Table 1) (Salomon et al. 2005, 2006, Taillieu et al. 2006, Tomlinson et al. 2010, Deloison et al. 2012). Alternative contrast agents that do not cross the placenta are emerging and are currently tested in rat.

Alternative approaches to the use of contrast agents include the use of arterial spin labelling (ASL) MRI that measures tissue perfusion using the protons of water within arterial blood as endogenous markers. Using this method, values of normal placental perfusion have been assessed in human pregnancies $(176 \pm 91 \mathrm{~mL} / \mathrm{min} / 100 \mathrm{~g}$
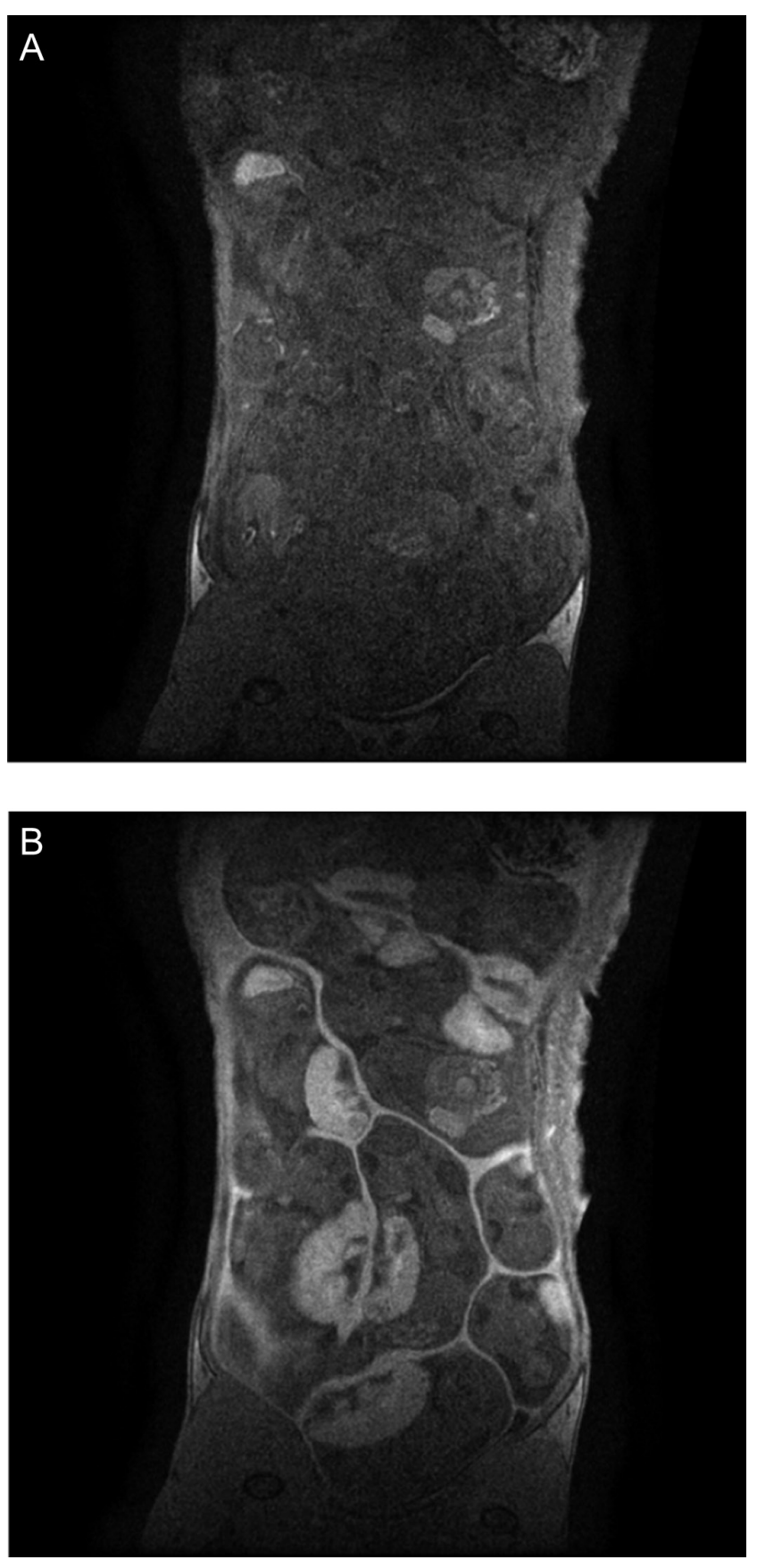

Figure 6 Evaluation of placental blood flow with magnetic resonance imaging (MRI) in the rabbit model before (A) and after (B) injection of contrast product.

of placental tissue) (Francis et al. 1998, Gowland et al. 1998, Avni et al. 2015).

Finally, the blood oxygen level-dependent (BOLD) MRI also uses blood as endogenous marker. This technique is based on haemoglobin, which possesses different magnetic properties depending on its deoxygenated/oxygenated state. BOLD MRI thus provides information on tissue oxygenation, which can complement information on tissue perfusion 
(Aimot-Macron et al. 2013, Chalouhi et al. 2013, Sinding et al. 2016).

Altogether, MRI provides a large field of view, multiplanar and volume capabilities, an improved soft tissue contrast as compared to ultrasound, with acceptable spatial and temporal resolutions of highcontrast images. Data are independent from the magnet and can be compared between places and machines. The limits of the technique are that it is expensive and complex and not widely available. Moreover, the necessity for the patient to remain motionless and the very load noise generated during the examination requires that animals are anaesthetised, which may modify haemodynamics. Finally, it is important to note that the spatial resolution obtained with MRI is much lower than the resolution obtained with superficial ultrasound probes. Future explorations may combine ultrasound and MRI approaches, although so far, these combinations are worthy for anatomical exploration but do not provide new functional insight (Salomon et al. 2013).

\section{Conclusion}

In conclusion, recent developments both in Doppler ultrasound and magnetic resonance-based techniques are giving new insight into the evaluation of placental vascularisation. Before their application in the clinical context, their evaluation on animal models is required. Because of their small size and despite the availability of micro-Doppler equipment, studies in mice are technically limited. The use of larger animals such as NHP, rabbits or ruminants remains a valuable alternative.

\section{Declaration of interest}

The authors of this paper declare that they have no conflict of interest. Authors are members of European COST action BM1308 SALAAM on Sharing Advances in Large Animal Models.

\section{Funding}

This research did not receive any specific grant from any funding agency in the public, commercial or not-for-profit sector.

\section{References}

Abramowicz JS 1997 Ultrasound contrast media and their use in obstetrics and gynecology. Ultrasound in Medicine and Biology 23 1287-1298. (doi:10.1016/S0301-5629(97)00201-9)

Abramowicz JS, Phillips DB, Jessee LN, Levene H, Parker KJ \& RK Miller 1999 Sonographic investigation of flow patterns in the perfused human placenta and their modulation by vasoactive agents with enhanced visualization by the ultrasound contrast agent Albunex. Journal of Clinical Ultrasound 27 513-522. (doi:10.1002/(SICI)10970096(199911/12)27:9<513::AID-JCU5>3.0.CO;2-A)
Aimot-Macron S, Salomon LJ, Deloison B, Thiam R, Cuenod CA, Clement O \& Siauve N 2013 In vivo MRI assessment of placental and foetal oxygenation changes in a rat model of growth restriction using blood oxygen level-dependent (BOLD) magnetic resonance imaging. European Radiology 23 1335-1342. (doi:10.1007/s00330-012-2712-y)

Alfirevic Z, Stampalija T \& Medley N 2015 Fetal and umbilical Doppler ultrasound in normal pregnancy. Cochrane Database of Systematic Reviews CD001450. (doi:10.1002/14651858.cd001450.pub4)

Arthuis CJ, Novell A, Escoffre JM, Patat F, Bouakaz A \& Perrotin F 2013 New insights into uteroplacental perfusion: quantitative analysis using Doppler and contrast-enhanced ultrasound imaging. Placenta 34 424-431. (doi:10.1016/j.placenta.2013.01.019)

Avni R, Neeman M \& Garbow JR 2015 Functional MRI of the placenta - from rodents to humans. Placenta 36 615-622. (doi:10.1016/j. placenta.2015.04.003)

Bairagi S, Quinn KE, Crane AR, Ashley RL, Borowicz PP, Caton JS, Redden RR, Grazul-Bilska AT \& Reynolds LP 2016 Maternal environment and placental vascularization in small ruminants. Theriogenology $\mathbf{8 6}$ 288-305. (doi:10.1016/j.theriogenology.2016.04.042)

Barker DJ, Eriksson JG, Forsen T \& Osmond C 2002 Fetal origins of adult disease: strength of effects and biological basis. International Journal of Epidemiology 31 1235-1239. (doi:10.1093/ije/31.6.1235)

Bell AW, McBride BW, Slepetis R, Early RJ \& Currie WB 1989 Chronic heat stress and prenatal development in sheep: I. Conceptus growth and maternal plasma hormones and metabolites. Journal of Animal Science 67 3289-3299. (doi:10.2527/jas1989.67123289x)

Bercoff J, Montaldo G, Loupas T, Savery D, Meziere F, Fink M \& Tanter M 2011 Ultrafast compound Doppler imaging: providing full blood flow characterization. IEEE Transactions on Ultrasonics, Ferroelectrics and Frequency Control 58 134-147. (doi:10.1109/TUFFC.2011.1780)

Bibeau K, Sicotte B, Beland M, Bhat M, Gaboury L, Couture R, St-Louis J \& Brochu M 2016 Placental underperfusion in a rat model of intrauterine growth restriction induced by a reduced plasma volume expansion. PLoS ONE 11 e0145982. (doi:10.1371/journal.pone.0145982)

Burton GJ, Charnock-Jones DS \& Jauniaux E 2009 Regulation of vascular growth and function in the human placenta. Reproduction 138 895-902. (doi:10.1530/REP-09-0092)

Cabezas López E, Martínez-Payo C, Engels Calvo V, San Frutos Llorente L \& Pérez-Medina T 2016 Reproducibility of first trimester threedimensional placental measurements. European Journal of Obstetrics and Gynecology and Reproductive Biology 201 156-160. (doi:10.1016/j. ejogrb.2016.03.034)

Carter AM 2007 Animal models of human placentation - a review. Placenta 28 (Supplement A) S41-S47. (doi:10.1016/j.placenta.2006.11.002)

Carter AM, Gothlin J \& Olin T 1971 An angiographic study of the structure and function of the uterine and maternal placental vasculature in the rabbit. Journal of Reproduction and Fertility 25 201-210. (doi:10.1530/ jrf.0.0250201)

Chalouhi GE, Alison M, Deloison B, Thiam R, Autret G, Balvay D, Cuenod CA, Clement O, Salomon LJ \& Siauve N 2013 Fetoplacental oxygenation in an intrauterine growth restriction rat model by using blood oxygen level-dependent MR imaging at 4.7 T. Radiology 269 122-129. (doi:10.1148/radiol.13121742)

Charnock-Jones DS, Kaufmann P \& Mayhew TM 2004 Aspects of human fetoplacental vasculogenesis and angiogenesis. I. Molecular regulation. Placenta 25 103-113. (doi:10.1016/j.placenta.2003.10.004)

Chavatte-Palmer P \& Tarrade A 2016 Placentation in different mammalian species. Annales d'Endocrinologie 77 67-74. (doi:10.1016/j. ando.2016.04.006)

Clark DA 2014 The use and misuse of animal analog models of human pregnancy disorders. Journal of Reproductive Immunology 103 1-8. (doi:10.1016/j.jri.2014.02.006)

Dar P, Gebb J, Reimers L, Bernstein PS, Chazotte C \& Merkatz IR 2010 First-trimester 3-dimensional power Doppler of the uteroplacental circulation space: a potential screening method for preeclampsia. American Journal of Obstetrics and Gynecology 203238 e231-e237. (doi:10.1016/j.ajog.2010.06.006)

Dekan S, Linduska N, Kasprian G \& Prayer D 2012 MRI of the placenta - a short review. Wiener Medizinische Wochenschrift 162 225-228. (doi:10.1007/s10354-012-0073-4)

Deloison B, Siauve N, Aimot S, Balvay D, Thiam R, Cuenod CA, Ville Y, Clement O \& Salomon LJ 2012 SPIO-enhanced magnetic resonance 
imaging study of placental perfusion in a rat model of intrauterine growth restriction. BJOG: International Journal of Obstetrics and Gynaecology 119 626-633. (doi:10.1111/j.1471-0528.2011.03251.x)

De Paula CFS, Ruano R, Campos JADB, Zugaib M 2009 Quantitative analysis of placental vasculature by three-dimensional power Doppler ultrasonography in normal pregnancies from 12 to 40 weeks of gestation. Placenta 30 142-148. (doi:10.1016/j.placenta.2008.11.010)

Di Salvo P, Bocci F, Zelli R \& Polisca A 2006 Doppler evaluation of maternal and fetal vessels during normal gestation in the bitch. Research in Veterinary Science 81 382-388. (doi:10.1016/j.rvsc.2006.03.004)

Duan J, Chabot-Lecoanet AC, Perdriolle-Galet E, Christov C, Hossu G, Cherifi A \& Morel O 2016 Utero-placental vascularisation in normal and preeclamptic and intra-uterine growth restriction pregnancies: third trimester quantification using 3D power Doppler with comparison to placental vascular morphology (EVUPA): a prospective controlled study. BMJ Open 6 e009909. (doi:10.1136/bmjopen-2015-009909)

Duncan SLB \& Lewis BV 1969 Maternal placental and myometrial blood flow in the pregnant rabbit. Journal of Physiology 202 471-481. (doi:10.1113/jphysiol.1969.sp008821)

Eixarch E, Hernandez-Andrade E, Crispi F, Illa M, Torre I, Figueras F \& Gratacos E 2011 Impact on fetal mortality and cardiovascular Doppler of selective ligature of uteroplacental vessels compared with undernutrition in a rabbit model of intrauterine growth restriction. Placenta 32 304-309. (doi:10.1016/j.placenta.2011.01.014)

Fonseca BM, Correia-da-Silva G \& Teixeira NA 2012 The rat as an animal model for fetoplacental development: a reappraisal of the postimplantation period. Reproductive Biology 12 97-118. (doi:10.1016/ S1642-431X(12)60080-1)

Francis ST, Duncan KR, Moore RJ, Baker PN, Johnson IR \& Gowland PA 1998 Non-invasive mapping of placental perfusion. Lancet 351 1397-1399. (doi:10.1016/S0140-6736(97)07089-X)

Frias AE, Morgan TK, Evans AE, Rasanen J, Oh KY, Thornburg KL \& Grove KL 2011 Maternal high-fat diet disturbs uteroplacental hemodynamics and increases the frequency of stillbirth in a nonhuman primate model of excess nutrition. Endocrinology 152 2456-2464. (doi:10.1210/en.20101332)

Giannico AT, Lima L, Lange RR, Froes TR \& Montiani-Ferreira F 2014 Proven cardiac changes during death-feigning (tonic immobility) in rabbits (Oryctolagus cuniculus). Journal of Comparative Physiology A: Neuroethology, Sensory, Neural, and Behavioral Physiology 200 305-310. (doi:10.1007/s00359-014-0884-4)

Gopalakrishnan K, Mishra JS, Chinnathambi V, Vincent KL, Patrikeev I, Motamedi M, Saade GR, Hankins GD \& Sathishkumar K 2016 Elevated testosterone reduces uterine blood flow, spiral artery elongation, and placental oxygenation in pregnant rats. Hypertension 67 630-639. (doi:10.1186/s40168-016-0173-2)

Gowland PA, Francis ST, Duncan KR, Freeman AJ, Issa B, Moore RJ, Bowtell RW, Baker PN, Johnson IR \& Worthington BS 1998 In vivo perfusion measurements in the human placenta using echo planar imaging at $0.5 \mathrm{~T}$. Magnetic Resonance in Medicine 40 467-473. (doi:10.1002/mrm.1910400318)

Gudmundsson S, Dubiel M \& Sladkevicius P 2009 Placental morphologic and functional imaging in high-risk pregnancies. Seminars in Perinatology 33 270-280. (doi:10.1053/j.semperi.2009.04.005)

Guiot C, Gaglioti P, Oberto M, Piccoli E, Rosato R \& Todros T 2008 Is three-dimensional power Doppler ultrasound useful in the assessment of placental perfusion in normal and growth-restricted pregnancies? Ultrasound in Obstetrics and Gynecology 31 171-176. (doi:10.1002/ uog.5212)

Hernandez-Andrade E, Ahn H, Szalai G, Korzeniewski SJ, Wang B, King M, Chaiworapongsa T, Than NG \& Romero R 2014 Evaluation of uteroplacental and fetal hemodynamic parameters throughout gestation in pregnant mice using high-frequency ultrasound. Ultrasound in Medicine and Biology 40 351-360. (doi:10.1016/j.ultrasmedbio.2013.09.026)

Hua X, Zhu LP, Li R, Zhong H, Xue YF \& Chen ZH 2009 Effects of diagnostic contrast-enhanced ultrasound on permeability of placental barrier: a primary study. Placenta 30 780-784. (doi:10.1016/j. placenta.2009.06.009)

Jaffe R 2001 Development of early uteroplacental circulation. Early Pregnancy 5 34-35.

Jaffe R, Jauniaux E \& Hustin J 1997 Maternal circulation in the first-trimester human placenta - myth or reality? American Journal of Obstetrics and Gynecology 176 695-705. (doi:10.1016/S0002-9378(97)70572-6)
Kanal E, Barkovich AJ, Bell C, Borgstede JP, Bradley WG Jr, Froelich JW, Gimbel JR, Gosbee JW, Kuhni-Kaminski E, Larson PA et al. 2013 ACR guidance document on MR safe practices: 2013. Journal of Magnetic Resonance Imaging 37 501-530. (doi:10.1002/jmri.24011)

Keator CS, Lindner JR, Belcik JT, Bishop CV \& Slayden OD 2011 Contrast-enhanced ultrasound reveals real-time spatial changes in vascular perfusion during early implantation in the macaque uterus. Fertility and Sterility 95 1316-1321, e1311-e1313. (doi:10.1016/j. fertnstert.2011.01.040)

Klewitz J, Struebing C, Rohn K, Goergens A, Martinsson G, Orgies F, Probst J, Hollinshead F, Bollwein H \& Sieme H 2015 Effects of age, parity, and pregnancy abnormalities on foal birth weight and uterine blood flow in the mare. Theriogenology 83 721-729. (doi:10.1016/j. theriogenology.2014.11.007)

Kulandavelu S, Whiteley KJ, Bainbridge SA, Qu D \& Adamson SL 2013 Endothelial NO synthase augments fetoplacental blood flow, placental vascularization, and fetal growth in mice. Hypertension 61 259-266. (doi:10.1161/HYPERTENSIONAHA.112.201996)

Lashley CJ, Supik DA, Atkinson JT, Murphy RJ \& O'Hagan KP 2015 Effect of pregnancy on the uterine vasoconstrictor response to exercise in rats. Physiological Reports 3 e12337. (doi:10.14814/phy2.12337)

Lecarpentier E, Morel O, Tarrade A, Dahirel M, Bonneau M, Gayat E, Evain-Brion D, Chavatte-Palmer P \& Tsatsaris V 2012 Quantification of utero-placental vascularization in a rabbit model of IUGR with three-dimensional power Doppler angiography. Placenta 33 769-775. (doi:10.1016/j.placenta.2012.06.013)

Llurba E, Sanchez O, Dominguez C, Soro G, Goya M, Alijotas-Reig J \& Cabero L 2013 Smoking during pregnancy: changes in mid-gestation angiogenic factors in women at risk of developing preeclampsia according to uterine artery Doppler findings. Hypertension in Pregnancy 32 50-59. (doi:10.3109/10641955.2012.704107)

Lopez-Tello J, Barbero A, Gonzalez-Bulnes A, Astiz S, Rodriguez M, Formoso-Rafferty N, Arias-Alvarez M \& Rebollar PG 2015 Characterization of early changes in fetoplacental hemodynamics in a diet-induced rabbit model of IUGR. Journal of Developmental Origins of Health and Disease 6 454-461. (doi:10.1017/ S2040174415001385)

Ma Y, Zhu MJ, Zhang L, Hein SM, Nathanielsz PW \& Ford SP 2010 Maternal obesity and overnutrition alter fetal growth rate and cotyledonary vascularity and angiogenic factor expression in the ewe. American Journal of Physiology: Regulatory, Integrative and Comparative Physiology 299 R249-R258. (doi:10.1152/ajpregu.00498.2009)

Makris A, Thornton C, Thompson J, Thomson S, Martin R, Ogle R, Waugh R, McKenzie P, Kirwan P \& Hennessy A 2007 Uteroplacental ischemia results in proteinuric hypertension and elevated sFLT-1. Kidney International 71 977-984. (doi:10.1038/sj.ki.5002175)

Matijevic R \& Johnston T 1999 In vivo assessment of failed trophoblastic invasion of the spiral arteries in pre-eclampsia. British Journal of Obstetrics and Gynaecology 106 78-82. (doi:10.1111/j.1471-0528.1999. tb08089.x)

Mayhew TM, Charnock-Jones DS \& Kaufmann P 2004 Aspects of human fetoplacental vasculogenesis and angiogenesis. III. Changes in complicated pregnancies. Placenta 25 127-139. (doi:10.1016/j. placenta.2003.10.010)

McArdle AM, Denton KM, Maduwegedera D, Moritz K, Flower RL \& Roberts CT 2009 Ontogeny of placental structural development and expression of the renin-angiotensin system and 11 [beta]HSD2 genes in the rabbit. Placenta 30 590-598. (doi:10.1016/j. placenta.2009.04.006)

Mevissen M, Buntenkotter S \& Loscher W 1994 Effects of static and timevarying $(50-\mathrm{Hz})$ magnetic fields on reproduction and fetal development in rats. Teratology 50 229-237. (doi:10.1002/tera.1420500308)

Morel O, Pachy F, Chavatte-Palmer P, Bonneau M, Gayat E, Laigre P, Evain-Brion D \& Tsatsaris V 2010 Correlation between uteroplacental three-dimensional power Doppler indices and true uterine blood flow: evaluation in a pregnant sheep model. Ultrasound in Obstetrics and Gynecology 36 635-640. (doi:10.1002/uog.7741)

Morel O, Grange G, Fresson J, Schaaps JP, Foidart JM, Cabrol D \& Tsatsaris V 2011 Vascularization of the placenta and the sub-placental myometrium: feasibility and reproducibility of a three-dimensional power Doppler ultrasound quantification technique. A pilot study. Journal of Maternal-Fetal and Neonatal Medicine 24 284-290. (doi:10.3 109/14767058.2010.486845) 
Muhler MR, Clement O, Salomon LJ, Balvay D, Autret G, Vayssettes C, Cuenod CA \& Siauve N 2011 Maternofetal pharmacokinetics of a gadolinium chelate contrast agent in mice. Radiology 258 455-460. (doi:10.1148/radiol.10100652)

Nautrup CP 1998 Doppler ultrasonography of canine maternal and fetal arteries during normal gestation. Journal of Reproduction and Fertility 112 301-314. (doi:10.1530/jrf.0.1120301)

Nesbitt AE, Murphy RJ \& O'Hagan KP 2005 Effect of gestational stage on uterine artery blood flow during exercise in rabbits. Journal of Applied Physiology (1985) 99 2159-2165. (doi:10.1152/ japplphysiol.00236.2005)

Neto RM \& Ramos JG 2016 3D power Doppler ultrasound in early diagnosis of preeclampsia. Pregnancy Hypertension 6 10-16. (doi:10.1016/j. preghy.2015.11.003)

Nusken KD, Dotsch J, Rauh M, Rascher W \& Schneider H 2008 Uteroplacental insufficiency after bilateral uterine artery ligation in the rat: impact on postnatal glucose and lipid metabolism and evidence for metabolic programming of the offspring by sham operation. Endocrinology 149 1056-1063. (doi:10.1210/en.2007-0891)

Osmanski BF, Lecarpentier E, Montaldo G, Tsatsaris V, Chavatte-Palmer P \& Tanter M 2015 Discriminative imaging of maternal and fetal blood flow within the placenta using ultrafast ultrasound. Scientific Reports $\mathbf{5}$ 13394. (doi:10.1038/srep13394)

Panarace M, Garnil C, Marfil M, Jauregui G, Lagioia J, Luther E \& Medina M 2006 Transrectal Doppler sonography for evaluation of uterine blood flow throughout pregnancy in 13 cows. Theriogenology 66 2113-2119. (doi:10.1016/j.theriogenology.2006.03.040)

Polisca A, Scotti L, Orlandi R, Brecchia G \& Boiti C 2010 Doppler evaluation of maternal and fetal vessels during normal gestation in rabbits. Theriogenology 73 358-366. (doi:10.1016/j. theriogenology.2009.09.019)

Pomorski M, Zimmer M, Fuchs T, Florjanski J, Pomorska M, Tomialowicz M \& Milnerowicz-Nabzdyk E 2014 Quantitative assessment of placental vasculature and placental volume in normal pregnancies with the use of 3D Power Doppler. Advances in Medical Sciences 59 23-27. (doi:10.1016/j.advms.2013.06.002)

Poret-Bazin H, Simon EG, Bleuzen A, Dujardin PA, Patat F \& Perrotin F 2013 Decrease of uteroplacental blood flow after feticide during second-trimester pregnancy termination with complete placenta previa: quantitative analysis using contrast-enhanced ultrasound imaging. Placenta 34 1113-1115. (doi:10.1016/j.placenta.2013.08.002)

Ragavendra N \& Tarantal AF 2001 Intervillous blood flow in the third trimester gravid rhesus monkey (Macaca mulatta): use of sonographic contrast agent and harmonic imaging. Placenta 22 200-205. (doi:10.1053/plac.2000.0605)

Redmer DA, Luther JS, Milne JS, Aitken RP, Johnson ML, Borowicz PP, Borowicz MA, Reynolds LP \& Wallace JM 2009 Fetoplacental growth and vascular development in overnourished adolescent sheep at day 50, 90 and 130 of gestation. Reproduction 137 749-757. (doi:10.1530/REP08-0516)

Reynolds LP \& Redmer DA 1995 Utero-placental vascular development and placental function. Journal of Animal Science 73 1839-1851. (doi:10.2527/1995.7361839x)

Roberts VH, Rasanen JP, Novy MJ, Frias A, Louey S, Morgan TK, Thornburg KL, Spindel ER \& Grigsby PL 2012 Restriction of placental vasculature in a non-human primate: a unique model to study placental plasticity. Placenta 33 73-76. (doi:10.1016/j.placenta.2011.10.003)

Roberts VH, Lo JO, Salati JA, Lewandowski KS, Lindner JR, Morgan TK \& Frias AE 2016 Quantitative assessment of placental perfusion by contrast-enhanced ultrasound in macaques and human subjects American Journal of Obstetrics and Gynecology 214369 e361-e368. (doi:10.1016/j.ajog.2015.10.731)

Robinson JS, Kingston EJ, Jones CT \& Thorburn GD 1979 Studies on experimental growth retardation in sheep. The effect of removal of a endometrial caruncles on fetal size and metabolism. Journal of Developmental Physiology 1 379-398.

Salavati N, Sovio U, Mayo RP, Charnock-Jones DS \& Smith GC 2016 The relationship between human placental morphometry and ultrasonic measurements of utero-placental blood flow and fetal growth. Placenta 38 41-48. (doi:10.1016/j.placenta.2015.12.003)

Salomon LJ, Siauve N, Balvay D, Cuenod CA, Vayssettes C, Luciani A, Frija G, Ville Y \& Clement O 2005 Placental perfusion MR imaging with contrast agents in a mouse model. Radiology 235 73-80. (doi:10.1148/ radiol.2351040192)

Salomon LJ, Siauve N, Taillieu F, Balvay D, Vayssettes C, Frija G, Ville Y, Cuenod CA \& Clement O 2006 In vivo dynamic MRI measurement of the noradrenaline-induced reduction in placental blood flow in mice. Placenta 27 1007-1013. (doi:10.1016/j.placenta.2005.10.007)

Salomon LJ, Bernard JP, Millischer AE, Sonigo P, Brunelle F, Boddaert N \& Ville Y 2013 MRI and ultrasound fusion imaging for prenatal diagnosis. American Journal of Obstetrics and Gynecology 209148 e141-e149. (doi:10.1016/j.ajog.2013.05.031)

Savasan ZA, Goncalves LF \& Bahado-Singh RO 2014 Second- and thirdtrimester biochemical and ultrasound markers predictive of ischemic placental disease. Seminars in Perinatology 38 167-176. (doi:10.1053/j. semperi.2014.03.008)

Schaaps JP \& Tsatsaris V 2001 Uteroplacental vascularization. Gynécologie Obstétrique and Fertilité 29 509-511.

SchmiedI UP, Komarniski K, Winter TC, Luna JA, Cyr DR, Ruppenthal G \& Schlief R 1998 Assessment of fetal and placental blood flow in primates using contrast enhanced ultrasonography. Journal of Ultrasound in Medicine 17 75-80; discussion 81-72.

Scotti L, Di Salvo P, Bocci F, Pieramati C \& Polisca A 2008 Doppler evaluation of maternal and foetal vessels during normal gestation in queen. Theriogenology 69 1111-1119. (doi:10.1016/j. theriogenology.2008.01.025)

Simpson NA, Nimrod C, De Vermette R, Leblanc C \& Fournier J 1998 Sonographic evaluation of intervillous flow in early pregnancy: use of echo-enhancement agents. Ultrasound in Obstetrics and Gynecology 11 204-208. (doi:10.1046/j.1469-0705.1998.11030204.x)

Sinding M, Peters DA, Frokjaer JB, Christiansen OB, Petersen A, Uldbjerg N \& Sorensen A 2016 Placental magnetic resonance imaging $\mathrm{T} 2 *$ measurements in normal pregnancies and in those complicated by fetal growth restriction. Ultrasound in Obstetrics and Gynecology 47 748-754. (doi:10.1002/uog.14917)

Taillieu F, Salomon LJ, Siauve N, Clement O, Faye N, Balvay D, Vayssettes C, Frija G, Ville Y \& Cuenod CA 2006 Placental perfusion and permeability: simultaneous assessment with dual-echo contrastenhanced MR imaging in mice. Radiology 241 737-745. (doi:10.1148/ radiol.2413051168)

Tanter M \& Fink M 2014 Ultrafast imaging in biomedical ultrasound. IEEE Transactions on Ultrasonics, Ferroelectrics and Frequency Control 61 102-119. (doi:10.1109/TUFFC.2014.2882)

Tarrade A, Lecarpentier E, Gil S, Morel O, Zahr N, Dahirel M, Tsatsaris V \& Chavatte-Palmer P 2014 Analysis of placental vascularization in a pharmacological rabbit model of IUGR induced by L-NAME, a nitric oxide synthase inhibitor. Placenta 35 254-259. (doi:10.1016/j. placenta.2014.01.013)

Tocchio S, Kline-Fath B, Kanal E, Schmithorst VJ \& Panigrahy A 2015 MRI evaluation and safety in the developing brain. Seminars in Perinatology 39 73-104. (doi:10.1053/j.semperi.2015.01.002)

Tomlinson TM, Garbow JR, Anderson JR, Engelbach JA, Nelson DM \& Sadovsky Y 2010 Magnetic resonance imaging of hypoxic injury to the murine placenta. American Journal of Physiology: Regulatory, Integrative and Comparative Physiology 298 R312-R319. (doi:10.1152/ ajpregu.00425.2009)

Tonni G, Martins WP, Guimaraes Filho H \& Araujo Junior E 2015 Role of 3-D ultrasound in clinical obstetric practice: evolution over 20 years. Ultrasound in Medicine and Biology 41 1180-1211. (doi:10.1016/j. ultrasmedbio.2014.12.009)

Tuuli MG, Longtine MS \& Nelson DM 2011 Review: oxygen and trophoblast biology - a source of controversy. Placenta 32 (Supplement 2) S109-S118. (doi:10.1016/j.placenta.2010.12.013)

Udesen J, Gran F, Hansen KL, Jensen JA, Thomsen C \& Nielsen MB 2008 High frame-rate blood vector velocity imaging using plane waves: simulations and preliminary experiments. IEEE Transactions on Ultrasonics, Ferroelectrics and Frequency Control 55 1729-1743. (doi:10.1109/TUFFC.2008.858)

Valentino SA, Tarrade A, Aioun J, Mourier E, Richard C, Dahirel M, Rousseau-Ralliard D, Fournier N, Aubriere MC, Lallemand MS et al. 2016 Maternal exposure to diluted diesel engine exhaust alters placental function and induces intergenerational effects in rabbits. Particle and Fibre Toxicology 13 39. (doi:10.1186/s12989016-0151-7) 
Venditti CC, Casselman R, Murphy MS, Adamson SL, Sled JG \& Smith GN 2013 Chronic carbon monoxide inhalation during pregnancy augments uterine artery blood flow and uteroplacental vascular growth in mice. American Journal of Physiology: Regulatory, Integrative and Comparative Physiology 305 R939-R948. (doi:10.1152/ajpregu.00204.2013)

Wallace JM, Milne JS, Matsuzaki M \& Aitken RP 2008 Serial measurement of uterine blood flow from mid to late gestation in growth restricted pregnancies induced by overnourishing adolescent sheep dams. Placenta 29 718-724. (doi:10.1016/j.placenta.2008.05.006)

Yan T, Cui K, Huang X, Ding S, Zheng Y, Luo Q, Liu X \& Zou L 2014 Assessment of therapeutic efficacy of miR-126 with contrast-enhanced ultrasound in preeclampsia rats. Placenta 35 23-29. (doi:10.1016/j. placenta.2013.10.017)

Zhou YJ, Yuan ML, Li R, Zhu LP \& Chen ZH 2013 Real-time placental perfusion on contrast-enhanced ultrasound and parametric imaging analysis in rats at different gestation time and different portions of placenta. PLOS ONE 8 e58986. (doi:10.1371/journal. pone.0058986)

Zhu XL, Wang J, Jiang RZ \& Teng YC 2015 Pulsatility index in combination with biomarkers or mean arterial pressure for the prediction of pre-eclampsia: Systematic literature review and metaanalysis. Annals of Medicine 47 414-422. (doi:10.3109/07853890.2 015.1059483)

Received 8 August 2016

First decision 13 October 2016

Revised manuscript received 3 November 2016

Accepted 14 November 2016 